\title{
Clinical Aspects, Immunophenotypic Analysis and Survival Rate of Chronic Lymphocytic Leukaemia Patients in Erbil City, Iraq
}

$$
\text { الجوانب السريرية (الإكلينيكية)، تحليل النمط المناعي الظاهري ومعدل البقاء على الحياة لمرضى سرطان الدم الليمفاوي المزمن في مدينة أربيل، العراق }
$$

كاوه محمدامين حسن

ABSTRAC T: Objectives: Chronic lymphocytic leukaemia (CLL) is characterised by an accumulation of clonal B cells in the blood, bone marrow and lymphatic tissue. This study aimed to evaluate the clinical and immunophenotypic characteristics and survival rate of CLL patients. Methods: This retrospective study was conducted at the Nanakaly Hospital for Blood Diseases \& Oncology in Erbil, Iraq, between January 2011 and December 2017. A total of 105 CLL patients were assessed to determine clinical presentation and staging, immunophenotype and survival rate. Results: The median age of the patients was 65 years and $63.8 \%$ were male. The main clinical presentations were splenomegaly (64.8\%), pallor (61.9\%) and lymphadenopathy (60\%). More than half of the patients presented at an advanced clinical stage according to the Rai and Binet staging systems (59.1\% and $55.2 \%$, respectively). All CLL cases expressed both cluster of differentiation (CD)19 and CD5, 67.6\% had monoclonal kappa light chains and $21 \%$ expressed CD38. The five-year overall survival (OS) rate was $61.3 \%$. The mean duration of five-year survival was 41.3 months (95\% confidence interval: $36.4-46.3$ months). There were no correlations between survival and sociodemographic, clinical or laboratory characteristics. Conclusion: In comparison to the existing Western literature, Iraqi CLL patients more frequently presented with hepatosplenomegaly and at a more advanced clinical stage. In addition, the five-year OS rate was much lower.

Keywords: Lymphoproliferative Disorders; Chronic Lymphocytic Leukemia; Immunophenotyping; Survival Rates; Iraq.

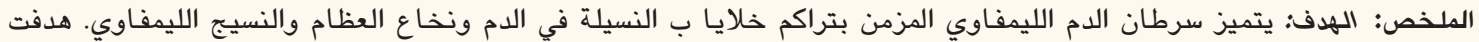

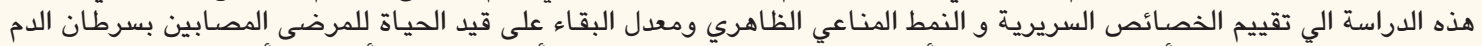

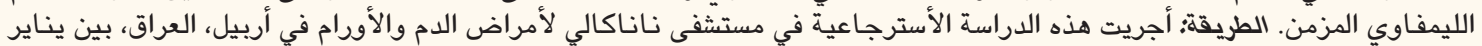

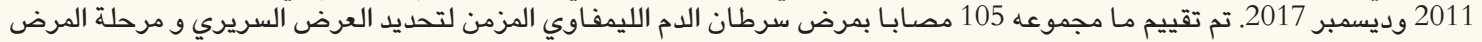

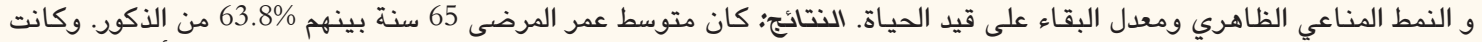

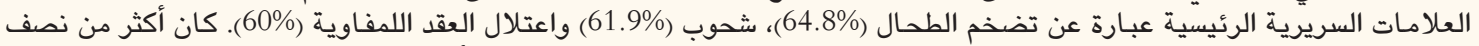

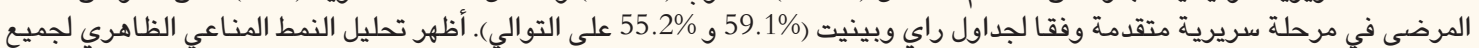

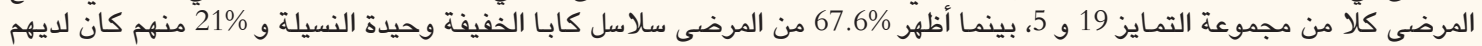

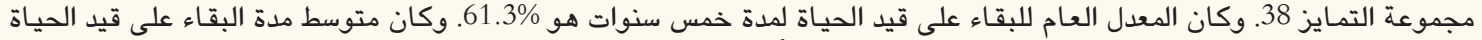

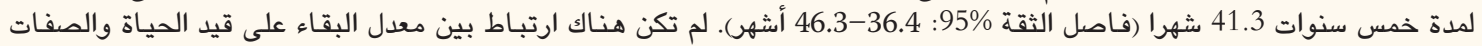

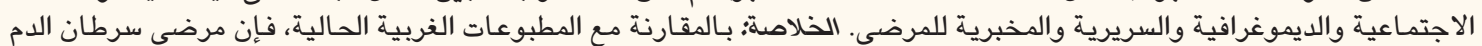

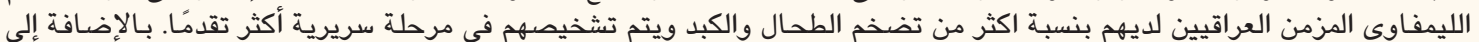

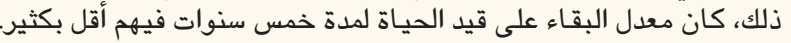

الكلمات المفتاحية؛ الاضطرابات التكاثرية الليمفاوية؛ سرطان الدم الليمفاوي المزمن؛ النمط المناعي الظاهري؛ معدلات البقاء على قيد الحياة؛ العراق.

\section{AdVANCES IN KNOWLEDGE}

This study provides the clinical and immunophenotypic findings and the survival rate of chronic lymphocytic leukaemia (CLL) patients in Erbil City, Iraq.

The current sample of CLL patients more frequently presented with hepatosplenomegaly, although less frequently with lymphadenopathy, compared to populations reported from Western countries. In addition, the Iraqi patients tended to present at a more advanced clinical stage and had lower survival rates than Western patients.

\section{Application to Patient Care}

The current results highlight the importance of implementing more advanced work-up tools for Iraqi CLL patients, such as a thorough cytogenetic evaluation. 
C HRONIC LYMPHOCYTIC LEUKAEMIA (CLL) IS the most common type of leukaemia among adults in Western countries; however, it is relatively rare in Asia., ${ }^{1,2}$ It is characterised by the build-up of lymphocytes in the blood, bone marrow and lymphatic tissue. The median age at diagnosis ranges from 67-72 years and the condition is more common in males. ${ }^{1,2}$ The clinical course of CLL is highly variable, ranging from no symptoms to the rapid development of features of high-risk disease. ${ }^{3}$ Lymph node swelling is the most common presenting feature of CLL, although fever, night sweats and weight loss are sometimes seen. The most common physical findings are lymphadenopathy, splenomegaly and, less frequently, hepatomegaly. ${ }^{3}$

A diagnosis of CLL can be established via a complete blood count $(\mathrm{CBC})$ showing the progressive accumulation of clonal B cells (>5,000 B lymphocytes/mL) over a period of at least three months and an immunophenotypic study demonstrating clonal lymphocytes expressing B cell markers and cluster of differentiation (CD)5. Both the modified Rai and Binet clinical staging systems are widely used to classify CLL patients into different prognostic groups according to the extent of lymph node involvement, enlargement of the liver and/or spleen and blood findings (i.e. anaemia and thrombocytopaenia).,5

The median survival rate for patients with CLL ranges from 18 months to more than 10 years, depending on prognostic factors like age, gender, disease stage, performance status, lymphocyte doubling time, absolute lymphocyte count (ALC) and $\beta-2$ microglobulin serum levels. ${ }^{7}$ Furthermore, the expression of certain biological markers such as CD38 or CD49d, deletion of chromosome $17 \mathrm{p} 13$ and the mutation status of the immunoglobulin heavy-chain variable region, tumour protein53 (TP53), Notch homolog 1, splicing factor-3B subunit-1 (SF3B1), baculoviral inhibitor of apoptosis protein-1 repeat-containing protein-3 (BIRC3), myeloid differentiation primary response 88 and zeta chain $T$ cell receptorassociated protein kinase-70 (ZAP70) genes also have a prognostic impact. ${ }^{8}$ The current study aimed to assess and compare the clinical characteristics, immunophenotypic findings and survival rate of CLL patients in Erbil, Iraq, with previously reported international and regional data.

\section{Methods}

This retrospective study was carried out between January 2011 and December 2017 at the Nanakaly Hospital for Blood Diseases \& Oncology, a regional referral hospital for adult and paediatric patients with benign and malignant haematology and solid oncology disorders in Erbil, Iraq. All patients attending the hospital during the study period and diagnosed with CLL as confirmed by CBC and immunophenotyping were invited to participate in the study.

The main clinical presentation and characteristics of each patient was documented, including the presence of lymphadenopathy, pallor, hepatomegaly and splenomegaly. In addition, the patients underwent a $\mathrm{CBC}$ and immunophenotyping study by flow cytometry using a FACSCanto II flow cytometer device (BD Biosciences, San Jose, California, USA) and/or immunohistochemistry. The laboratory analysis included a reticulocyte count, erythrocyte sedimentation rate, direct antiglobulin test (DAT), bone marrow examination, serology tests (i.e. to determine lactate dehydrogenase [LDH] levels) and liver and renal function tests. In indicated cases, patients also underwent various imaging studies, including ultrasonography of the abdomen, a chest X-ray and computed tomography. In each case, clinical stage was determined

Table 1: Baseline characteristics of chronic lymphocytic leukaemia patients in Erbil, Iraq $(\mathrm{N}=105)$

\begin{tabular}{lc} 
Characteristic & $\mathbf{n}(\%)$ \\
Age in years & \\
$<50$ & $10(9.5)$ \\
$50-59$ & $21(20)$ \\
$60-69$ & $40(38.1)$ \\
$\geq 70$ & $34(32.4)$ \\
Gender & \\
Male & $67(63.8)$ \\
Female & $38(36.2)$ \\
Clinical presentation* & \\
Splenomegaly ${ }^{\dagger}$ & $68(64.8)$ \\
Pallor & $65(61.9)$ \\
Peripheral lymphadenopathy & $63(60)$ \\
Hepatomegaly & $23(21.9)$ \\
Rai clinical stage & \\
0 & $19(18.1)$ \\
I & $43(41)$ \\
II & $9(8.6)$ \\
III & $20(19)$ \\
IV & \\
\hline
\end{tabular}

Binet clinical stage
A
$29(27.6)$
B
C

*Percentages do not add up to $100 \%$ as some patients may have had more than one clinical presentation. ${ }^{\dagger}$ For patients with splenomegaly, the mean longitudinal axis of the spleen was $14.7 \pm 3.4 \mathrm{~cm}$. 
Table 2: Laboratory results of chronic lymphocytic leukaemia patients in Erbil, Iraq $(\mathrm{N}=105)$

\begin{tabular}{|c|c|c|c|c|}
\hline Investigation & Mean \pm SD & Median & Range & Normal range \\
\hline Absolute lymphocyte count $\times 10^{9} / \mathrm{L}$ & $87 \pm 104.5$ & 58.5 & $6-462.5$ & $1-4.8$ \\
\hline Platelet count $\times 10^{9} / \mathrm{L}$ & $140 \pm 74.2$ & 115 & $30-382$ & $150-400$ \\
\hline Reticulocytes, \% & $2.1 \pm 2.0$ & 1.7 & $0.1-10$ & $0.5-1.5$ \\
\hline Erythrocyte sedimentation rate in $\mathrm{mm} /$ hour & $44.3 \pm 33.3$ & 37 & $2-145$ & $0-10 / 3-15^{*}$ \\
\hline Lactate dehydrogenase in U/L & $400.1 \pm 159.9$ & 378 & $108-905$ & $100-250$ \\
\hline Blood urea in $\mathrm{mg} / \mathrm{dL}$ & $44.2 \pm 21.3$ & 41 & $16.3-160$ & $15-40$ \\
\hline Serum creatinine in $\mathrm{mg} / \mathrm{dL}$ & $1 \pm 0.4$ & 1 & $0.3-3$ & $0.7-1.3$ \\
\hline
\end{tabular}

SD = standard deviation. *Males/females.

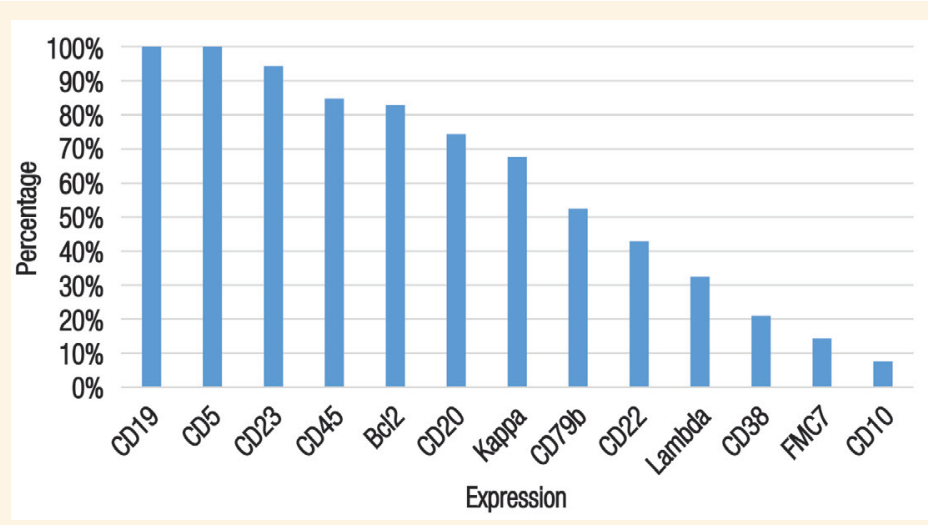

Figure 1: Immunophenotypic findings of chronic lymphocytic leukaemia patients in Erbil, Iraq $(\mathrm{N}=105)$. $C D=$ cluster of differentiation; $B c l 2=B$ cell lymphoma 2; FMC7 = Flinder Medical Centre-7.

Table 3: Treatment provided to chronic lymphocytic leukaemia patients in Erbil, Iraq $(\mathrm{N}=105)$

$\begin{array}{lc}\text { Treatment* } & \text { n (\%) } \\ \text { FCR } & 24(22.9) \\ \text { BR } & 19(18.1) \\ \text { FC } & 2(1.9) \\ \text { Chlorambucil } & 9(8.6) \\ \text { Chlorambucil plus prednisolone } & 10(9.5) \\ \text { Rituximab and chlorambucil } & 10(9.5) \\ \text { COP } & 4(3.8) \\ \text { Rituximab and COP } & 5(4.8) \\ \text { Rituximab and CHOP } & 7(6.7) \\ \text { Rituximab } & 2(1.9) \\ \text { No treatment } & 17(16.2)\end{array}$

$F C R=$ fludarabine, cyclophosphamide and rituximab; $B R=$ bendam ustine plus rituximab; $F C=$ fludarabine plus cyclophosphamide; $C O P=$ cyclophosphamide, oncovin and prednisolone; $C H O P=$ cyclophosphamide, hydroxydaunomycin, oncovin and prednisolone. "Percentages do not add up to $100 \%$ as four patients were treated with more than one protocol. according to both the Rai and Binet staging systems. ${ }^{5,6}$ Survival rates were calculated, including the overall survival (OS) rate over the study period and the fiveyear OS rate.

Data were analysed using the Statistical Package for the Social Sciences (SPSS), Version 22.0 (IBM Corp., Armonk, New York, USA). A Chi-squared test was used to compare associations between proportions. KaplanMeier survival curves were plotted and the log-rank Mantel-Cox test was used to compare mean survival times. A $P$ value of $\leq 0.050$ was considered statistically significant.

This study was approved by the Scientific and Ethical Committees of the College of Medicine, Hawler Medical University, Erbil.

\section{Results}

A total of 143 CLL patients attended the hospital during the study period. However, 38 patients were excluded due to a lack of adequate data or follow-up. As such, 
Table 4: Correlation between survival rate and selected characteristics among chronic lymphocytic leukaemia patients in Erbil, Iraq $(\mathrm{N}=105)$

\begin{tabular}{|c|c|c|c|}
\hline \multirow{2}{*}{ Characteristic } & \multicolumn{2}{|c|}{ n (\%) } & \multirow[t]{2}{*}{$P$ value } \\
\hline & $\begin{array}{l}\text { Survived } \\
(\mathbf{n}=71)\end{array}$ & $\begin{array}{c}\text { Died } \\
(\mathbf{n}=34)\end{array}$ & \\
\hline \multicolumn{4}{|l|}{ Age in years } \\
\hline$<50$ & $6(60)$ & $4(40)$ & \multirow{4}{*}{0.098} \\
\hline $50-59$ & $19(90.5)$ & $2(9.5)$ & \\
\hline $60-69$ & $25(62.5)$ & $15(37.5)$ & \\
\hline$\geq 70$ & $21(61.8)$ & $13(38.2)$ & \\
\hline \multicolumn{4}{|l|}{ Gender } \\
\hline Male & $43(64.2)$ & $24(35.8)$ & \multirow{2}{*}{0.163} \\
\hline Female & $28(73.7)$ & $10(26.3)$ & \\
\hline \multicolumn{4}{|c|}{ Lymphadenopathy } \\
\hline Yes & $41(65.1)$ & $22(34.9)$ & \multirow{2}{*}{0.496} \\
\hline No & $30(71.4)$ & $12(28.6)$ & \\
\hline \multicolumn{4}{|l|}{ Splenomegaly } \\
\hline Yes & $46(67.6)$ & $22(32.4)$ & \multirow{2}{*}{0.993} \\
\hline No & $25(67.6)$ & $12(32.4)$ & \\
\hline \multicolumn{4}{|l|}{ Hepatomegaly } \\
\hline Yes & $14(60.9)$ & $9(39.1)$ & \multirow{2}{*}{0.434} \\
\hline No & $57(69.5)$ & $25(30.5)$ & \\
\hline \multicolumn{4}{|l|}{ Rai clinical stage } \\
\hline 0 & $12(85.7)$ & $2(14.3)$ & \multirow{5}{*}{0.190} \\
\hline I & $4 \cdot(44.4)$ & $5(55.6)$ & \\
\hline II & $15(75)$ & $5(25)$ & \\
\hline III & $14(73.7)$ & $5(26.3)$ & \\
\hline IV & $26(60.5)$ & $17(39.5)$ & \\
\hline \multicolumn{4}{|c|}{ Binet clinical stage } \\
\hline A & $21(72.4)$ & $8(27.6)$ & \multirow{3}{*}{0.648} \\
\hline B & $13(72.2)$ & $5(27.8)$ & \\
\hline $\mathrm{C}$ & $37(63.8)$ & $21(36.2)$ & \\
\hline \multicolumn{4}{|l|}{ Hb level in $\mathrm{g} / \mathrm{dL}$} \\
\hline$\leq 11$ & $54(65.9)$ & $28(34.1)$ & \multirow{2}{*}{0.465} \\
\hline$>11$ & $17(73.9)$ & $6(26.1)$ & \\
\hline \multicolumn{4}{|l|}{$\mathrm{WBC} \times 10^{9} / \mathrm{L}$} \\
\hline$<65$ & $37(69.8)$ & $16(30.2)$ & \multirow{2}{*}{0.628} \\
\hline$\geq 65$ & $34(65.4)$ & $18(34.6)$ & \\
\hline \multicolumn{4}{|c|}{ Platelet count $\times 10^{9} / \mathrm{L}$} \\
\hline$<150$ & $44(69.8)$ & $19(30.2)$ & \multirow{2}{*}{0.551} \\
\hline$\geq 150$ & $27(64.3)$ & $15(35.7)$ & \\
\hline \multicolumn{4}{|l|}{$\mathrm{LDH}$ in $\mathrm{U} / \mathrm{L}$} \\
\hline$<250$ & $17(81)$ & 4 (19) & \multirow{2}{*}{0.144} \\
\hline$\geq 250$ & $54(64.3)$ & $30(35.7)$ & \\
\hline
\end{tabular}

$H b=$ haemoglobin WBC $=$ white blood cells; $L D H=$ lactate dehydrogenase.
105 patients were included in the final analysis. Of these, 67 (63.8\%) were male and 38 (36.2\%) were female. The mean age at presentation was $63.3 \pm 10.7$ years. Most patients $(70.5 \%)$ were $\geq 60$ years, with only $9.5 \%<50$ years. The age at diagnosis ranged from $28-81$ years old, with a median of 65 years. The main clinical presentations were splenomegaly (64.8\%) pallor (61.9\%) and lymphadenopathy (60\%). Hepatomegaly was observed in $21.9 \%$ of patients. Modified Rai staging showed a high risk (stage III or IV) of CLL in 59.1\%, an intermediate risk (stage I or II) in $27.6 \%$ and a low risk (stage 0 ) in $13.3 \%$ of patients. In terms of Binet staging, $55.2 \%$ of patients were stage $C, 17.1 \%$ were stage $B$ and $27.6 \%$ were stage A [Table 1]. Most patients (72.4\%) were from Erbil and other cities in the Kurdistan region of Iraq, while the rest were from other northern and western Iraqi cities.

The mean haemoglobin level was $10.6 \pm 2.3 \mathrm{~g} / \mathrm{dL}$ (range: $5-15.4 \mathrm{~g} / \mathrm{dL}$ ). Mean platelet and white blood cell counts were $140 \pm 74.2 \times 10^{9} / \mathrm{L}$ (range: $30-382 \times 10^{9} / \mathrm{L}$ ) and $94.8 \pm 106.6 \times 10^{9} / \mathrm{L}$ (range: $8.9-491 \times 10^{9} / \mathrm{L}$ ), respectively. The mean ALC was $87 \pm 104.5 \times 10^{9} / \mathrm{L}$ (range: $6-462.5 \times 10^{9} / \mathrm{L}$ ) [Table 2]. Overall, LDH levels were elevated in $82.8 \%$ of patients and $11.4 \%$ had autoimmune haemolytic anaemia (AIHA) with positive DAT results. Anaemia was observed in 83 (79.1\%) patients, comprising $83.6 \%$ and $71.1 \%$ of male and female patients, respectively. A total of 63 (60\%) and 28 (26.7\%) patients presented with thrombocytopaenia and incidental lymphocytosis, respectively. None of the patients had Richter's syndrome.

All patients underwent immunophenotyping analysis via flow cytometry and/or immunohistochemistry from either peripheral blood (79.1\%) or bone marrow (21\%) samples. All cases expressed both CD19 and CD5, while the vast majority expressed CD23 (94.3\%), CD45 (84.8\%) and B cell lymphoma 2 (82.9\%). About twothirds of the patients (67.6\%) expressed monoclonal kappa light chains, while just under one-third (32.4\%) expressed lambda chains. Only $21 \%$ of cases expressed CD38 [Figure 1]. In terms of treatment, most patients received either fludarabine, cyclophosphamide and rituximab (22.9\%) or bendamustine plus rituximab (18.1\%). The rest underwent various other chemotherapy protocols $(46.7 \%)$ or did not receive any treatment at all (16.2\%) [Table 3].

The mean follow-up period was 27.7 months. A total of 34 (32.4\%) patients died during the study period, of which 24 (70.6\%) were male and 10 (29.4\%) were female, resulting in an OS rate of $67.6 \%$. Although survival was greater among those aged $50-59$ years (90.5\% versus $60-62.5 \%$ in other age groups) and among females (73.7\% versus $64.2 \%$ in males), these differences were not statistically significant $(P=0.098$ and 0.163 , 


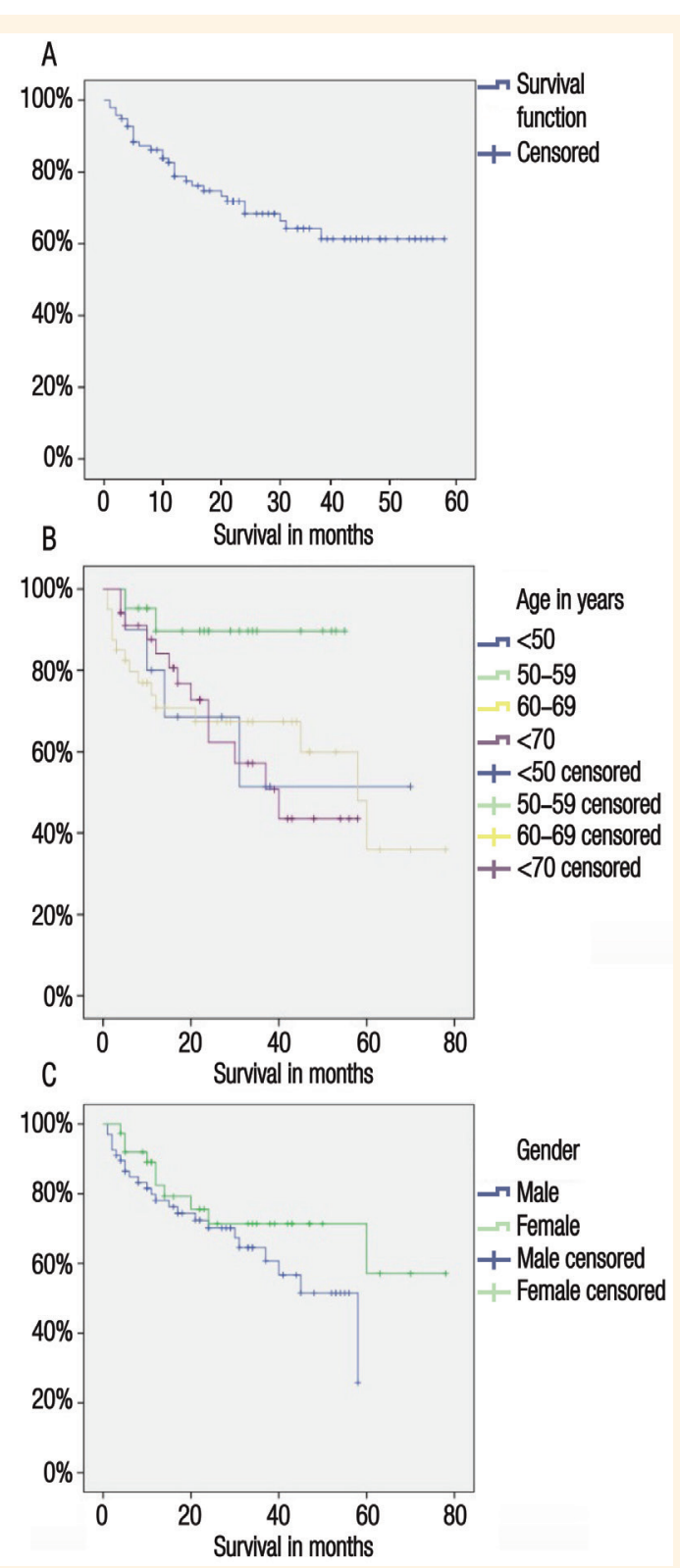

Figure 2: Kaplan-Meier survival curves showing (A) fiveyear overall survival (OS), (B) five-year OS by age group $(P=0.185)$ and $(C)$ five-year $\mathrm{OS}$ by gender $(P=0.163)$ among chronic lymphocytic leukaemia patients in Erbil, Iraq $(\mathrm{N}=105)$.

respectively). Other clinical and laboratory characteristics were also not significantly correlated with survival ( $P>0.050$ each) [Table 4]. The five-year OS rate was $61.3 \%$. The mean duration of five-year survival was 60 months (95\% confidence interval: 36.4-46.3 months); however, the median survival could not be estimated and could have occurred beyond the study period. The mean duration of survival was longer among females and those aged 50-59 years old; however, these differences were not statistically significant $(P=0.185$ and 0.163 , respectively) [Figure 2].

\section{Discussion}

In the current study, the median age at diagnosis of CLL patients in Erbil, Iraq, was similar to that reported in neighbouring countries such as Iran and Turkey (65 years versus 60.73 and 64 years, respectively). ${ }^{2,9}$ In contrast, the median age at diagnosis in Western countries is much higher, ranging from $67-72$ years old. ${ }^{1,10,11}$ However, the frequency of male CLL patients in the current study was identical to that reported in Italy (64\%). ${ }^{12}$ In terms of clinical presentation, splenomegaly (64.8\% versus 54\%) and hepatomegaly (21.9\% versus 14\%) were reported more frequently in the current study compared to Western patients, while lymphadenopathy was less frequent $(60 \%$ versus $87 \%) .^{3}$ In Turkey, rates of splenomegaly, hepatomegaly and lymphadenopathy differed at 55.4\%, 54.6\% and $79.2 \%$, respectively. ${ }^{9}$ In Iran, Payandeh et al. also reported varying rates of organomegaly (34\%) and lymphadenopathy (38.7\%). ${ }^{2}$ The diversity of clinical presentations in CLL and correlations with ethnicity have been well documented in previous research. ${ }^{13}$

The incidence of anaemia and AIHA in the current study (78.1\% and $11 \%$, respectively) was comparable to that reported in previous research in which AIHA was documented in up to $11 \%$ of late-stage CLL patients, with positive DAT results seen in up to $15 \%$ of patients. ${ }^{14}$ In the present study, $60 \%$ of patients had thrombocytopaenia; this finding is understandable given that most patients presented at an advanced clinical stage, such as Rai stage III or IV (59.1\%) or Binet stage C (55.2\%). According to data from other developing countries such as Iran, Turkey and India, patients in this region are often first seen at more advanced stages (38.5\%, 33.3\% and 41\%, respectively). ${ }^{2,15,16}$ However, in developed countries, only $10-20 \%$ of patients present at an advanced stage. ${ }^{17}$ These findings may indicate that routine $\mathrm{CBC}$ analysis is less frequently performed in developing countries or that hospitals in this region lack proper evaluation and management protocols or experience delays in the referral of patients with incidental lymphocytosis. It is also possible that there is a difference in the biology of the disease (e.g. in terms of such patients having a less mutated subtype of CLL). ${ }^{4}$

In the present study, most cases expressed CD19, CD5 and CD23, with CD79b less frequently expressed; these findings are consistent with the characteristic profile of CLL disease. ${ }^{18}$ For those patients not expressing CD23-considered atypical CLL cases-other markers could help to differentiate CLL from mantle cell lymphoma, such as the negative expression of Flinder Medical 
Centre-7. ${ }^{19}$ Overall, CD38 expression at any level is regarded as a poor prognostic indicator; it was expressed in $21 \%$ of cases in the present study, which is comparable to the findings of Hojjat Farsangi et al. $(27.6 \%){ }^{20}$ In the current study, $67.6 \%$ of patients had monoclonal kappa light chains, with $32.4 \%$ expressing lambda chains. Hojjat Fersangi et al. reported rates of expression of kappa and lambda chains to be $71.3 \%$ and $28.7 \%$, respectively, among Iranian CLL patients. ${ }^{20}$ Stamatopoulos et al. also reported similar findings in Greece. $^{21}$

The OS (67.6\%) in the current study was comparable to data reported from Iran (64\%), although the five-year OS rate (61.3\%) was higher than results from Turkey (36.5\%) and India (51\%).,22,23 However, data from Germany and the USA indicate much higher five-year relative survival rates $(80.2 \%$ and $82.4 \%$, respectively). ${ }^{24}$ The mean duration of five-year survival in the current study was 41.3 months, which is similar to data reported from Iran (38.5 months). ${ }^{2}$ This may be related to variations in a number of patient-related characteristics, such as clinical stage at diagnosis. The reason why the five-year OS rate in the present study was lower than the overall OS is likely because patients whom were more recently diagnosed (i.e. in 2015-2017) had not yet received their five-year follow-up at the time of the analysis.

Early diagnosis plays a major role in improving survival in CLL patients. ${ }^{25}$ Other possible causes for low five-year OS rates are the lack of availability of equipment to conduct thorough cytogenetic evaluations for factors known to have a prognostic impact—such as deletions of chromosomes 11q, 13q, 17p and trisomy 12 as well as TP53, NOTCH1, SF3B1 and BIRC3 gene mutations. ${ }^{8}$ In addition, insufficient access to adequate or novel chemotherapy agents like obinutuzumab, ibrutinib, idelalisib and venetoclax as a frontline treatment or for relapsed/refractory cases may negatively affect survival. ${ }^{26}$

No significant correlations were noted between survival rates and selected sociodemographic, clinical or laboratory characteristics in the present study. These findings partially agree with those previously reported by Shvidel et al.; however, they contradict de Faria et al.'s study. ${ }^{27,28}$ The difference between these findings is probably due to variations in sample size, the lack of genetic assessment conducted in the current study and the well-known impact of ethnicity. ${ }^{13}$ In addition, data regarding CD49d and ZAP70 expression, which have a major prognostic impact on CLL patients, were not available. ${ }^{8}$ Further research is therefore recommended to evaluate these factors.

\section{Conclusion}

The median age, male-to-female ratio and clinical and immunophenotypic characteristics of Iraqi CLL patients in the current study did not differ greatly from previous regional and international data; however, patients more frequently presented at an advanced stage and had a lower five-year OS rate compared to Western populations. In addition, Iraqi patients more frequently presented with organomegaly, including hepatomegaly, although less frequently with lymphadenopathy.

\section{CONFLICT OF INTEREST}

The authors declare no conflicts of interest.

\section{FUNDING}

No funding was received for this study.

\section{References}

1. Watson L, Wyld P, Catovsky D. Disease burden of chronic lymphocytic leukaemia within the European Union. Eur J Haematol 2008; 81:253-8. https://doi.org/10.1111/j.1600-0609.2008.01114.x.

2. Payandeh M, Sadeghi E, Sadeghi M. Survival and clinical aspects for patients with chronic lymphocytic leukemia in Kermanshah, Iran. Asian Pac J Cancer Prev 2015; 16:7987-90. https://doi.org/10.7314/APJCP.2015.16.17.7987

3. Abbott BL. Chronic lymphocytic leukemia: Recent advances in diagnosis and treatment. Oncologist 2006; 11:21-30. https://doi. org/10.1634/theoncologist.11-1-21.

4. Hallek M. Chronic lymphocytic leukemia: 2017 update on diagnosis, risk stratification, and treatment. Am I Hematol 2017; 92:946-65. https://doi.org/10.1002/ajh.24826.

5. Rai KR, Sawitsky A, Cronkite EP, Chanana AD, Levy RN, Pasternack BS. Clinical staging of chronic lymphocytic leukemia. Blood 1975; 46:219-34.

6. Binet JL, Auquier A, Dighiero G, Chastang C, Piguet H, Goasguen J, et al. A new prognostic classification of chronic lymphocytic leukemia derived from a multivariate survival analysis. Cancer 1981; 48:198-206. https://doi.org/10.1002/1 097-0142(19810701)48:1<198::AID-CNCR2820480131> 3.0.CO;2-V.

7. Wierda WG, O’Brien S, Wang X, Faderl S, Ferrajoli A, Do KA, et al. Characteristics associated with important clinical end points in patients with chronic lymphocytic leukemia at initial treatment. J Clin Oncol 2009; 27:1637-43. https://doi.org/10.1 200/JCO.2008.18.1701

8. Puente XS, Pinyol M, Quesada V, Conde L, Ordóñez GR, Villamor N, et al. Whole-genome sequencing identifies recurrent mutations in chronic lymphocytic leukaemia. Nature 2011; 475:101-5. https://doi.org/10.1038/nature10113.

9. Üsküdar Teke H, Üsküdar Cansu D, Akay OM, Gündüz E, Bal C, Gülbas Z. Clinico-hematological evaluation of 13 chronic lymphocytic leukemia patients in the central Anatolia region in Turkey. Turk Klin Tip Bilimleri Dergisi 2009; 29:64-9.

10. Eichhorst B, Robak T, Montserrat E, Ghia P, Hillmen P, Hallek M, et al. Chronic lymphocytic leukaemia: ESMO clinical practice guidelines for diagnosis, treatment and follow-up. Ann Oncol 2015; 26:v78-84. https://doi.org/10.1093/annonc/mdv303. 
11. Mulligan SP, Tam CS. Chronic lymphocytic leukemia: Diagnosis and clinical staging. In: Keating MJ, Tam CS, Eds. Advances in the Treatment of B-cell Chronic Lymphocytic Leukemia. London, UK: Future Medicine Ltd., 2012. Pp. 6-15. https://doi. org/10.2217/9781780840444

12. Molica S. Sex differences in incidence and outcome of chronic lymphocytic leukemia patients. Leuk Lymphoma 2006; 47:1477-80. https://doi.org/10.1080/10428190600555819.

13. Nabhan C, Ascherbrook-Kilfoy B, Chiu BC, Smith SM, Shanafelt TD, Evens AM, et al. The impact of race, ethnicity, age and sex on clinical outcome in chronic lymphocytic leukemia: A comprehensive Surveillance, Epidemiology, and End Results analysis in the modern era. Leuk Lymphoma 2014; 55:2778-84. https://doi.org/10.3109/10428194.2014.898758.

14. Diehl LF, Ketchum LH. Autoimmune disease and chronic lymphocytic leukemia: Autoimmune anemia, pure red cell aplasia, and autoimmune thrombocytopenia. Semin Oncol 1998; 25:80-97.

15. Tombak A, Tiftik N, Dogu MH, Sari I, Akay MO, Karagulle M, et al. The clinical characteristics and therapeutic outcomes of elderly patients with chronic lymphocytic leukemia: A retrospective multicenter study. Blood 2014; 124:5644.

16. Gogia A, Sharma A, Raina V, Kumar L, Vishnubhatla S, Gupta R et al. Assessment of 285 cases of chronic lymphocytic leukemia seen at single large tertiary center in Northern India. Leuk Lymphoma 2012; 53:1961-5. https://doi.org/10.3109/1042819 4.2012 .672734 .

17. Delgado J, Santacruz R, Baumann T, Montserrat E. New developments in chronic lymphocytic leukaemia diagnosis. Eur Oncol Haematol 2013; 9:114-18. https://doi.org/10.17925/EO H.2013.09.2.114.

18. Rodrigues CA, Gonçalves MV, Ikoma MR, Lorand-Metze I, Pereira AD, Farias DL, et al. Diagnosis and treatment of chronic lymphocytic leukemia: Recommendations from the Brazilian Group of Chronic Lymphocytic Leukemia. Rev Bras Hematol Hemoter 2016; 38:346-57. https://doi.org/10.1016/j.bjhh.2016.07.004.

19. Delgado J, Matutes E, Morilla AM, Morilla RM, OwusuAnkomah KA, Rafiq-Mohammed F, et al. Diagnostic significance of CD20 and FMC7 expression in B-cell disorders. Am J Clin Pathol 2003; 120:754-59. https://doi.org/10.1309/FNGCYEMJ-E3MA-E5L2
20. Hojjat Farsangi M, Jeddi-Tehrani M, Razavi SM, Sharifian RA, Shamsian Khoramabadi A, Rabbani H, et al. Immunophenotypic characterization of the leukemic B-cells from Iranian patients with chronic lymphocytic leukemia: Association between CD38 expression and disease progression. Iran J Immunol 2008; 5:25-35.

21. Stamatopoulos K, Belessi C, Hadzidimitriou A, Smilevska T, Kalagiakou E, Hatzi K, et al. Immunoglobulin light chain repertoire in chronic lymphocytic leukemia. Blood 2005; 106:3575-83. https://doi.org/10.1182/blood-2005-04-1511.

22. Pamuk ON, Pamuk GE, Soysal T, Ongören S, Başlar Z, Ferhanoğlu B, et al. Chronic lymphocytic leukemia in Turkey: Experience of a single center in Istanbul. South Med J 2004; 97:240-5. https://doi.org/10.1097/01.SMJ.0000053674.03385.B7.

23. Gogia A, Raina V, Gupta R, Gajendra S, Kumar L, Sharma A, et al. Prognostic and predictive significance of smudge cell percentage on routine blood smear in chronic lymphocytic leukemia. Clin Lymphoma Myeloma Leuk 2014; 14:514-17. https://doi.org/10.1016/j.clml.2014.02.007.

24. Pulte D, Castro FA, Jansen L, Luttmann S, Holleczek B, Nennecke A, et al. Trends in survival of chronic lymphocytic leukemia patients in Germany and the USA in the first decade of the twenty-first century. J Hematol Oncol 2016; 9:28. https://doi. org/10.1186/s13045-016-0257-2.

25. Molica S, Levato D. What is changing in the natural history of chronic lymphocytic leukemia? Haematologica 2001; 86:8-12.

26. Barrientos JC. Management of chronic lymphocytic leukemia in the elderly. Cancer Control 2015; 22:17-23. https://doi.org/1 $0.1177 / 107327481502204 s 04$

27. Shvidel L, Braester A, Bairey O, Rahimi-Levene N, Klepfish A, Herishanu Y, et al. Survival trends among 1,325 patients with chronic lymphocytic leukemia seen over the past 40 years in Israel. Am J Hematol 2011; 86:985-92. https://doi.org/10.1002/ ajh. 22160 .

28. de Faria JR, de Oliveira JS, Delbone de Faria RM, Silva MR, Goihman S, Yamamoto M, et al. Prognosis related to staging systems for chronic lymphocytic leukemia. Sao Paulo Med J 2000; 118:83-8. https://doi.org/10.1590/S1516-318020000004 00002 . 